\title{
Prototipagem Digital como recurso de ensino: Uma experiência pedagógica de projetos para turmas integradas de design, arquitetura e expressão gráfica
}

\author{
Digital prototyping as a teaching tool: A project-based pedagogical experience for integrated \\ classes of design, architecture and graphic expression
}

\author{
Pedro Martins Alessio \\ Universidade Federal de Pernambuco, Brasil \\ pedro.alessio@gmail.com \\ Letícia Teixeira Mendes \\ Universidade Federal de Pernambuco, Brasil \\ leticiamendes.edu@gmail.com
}

\author{
Natal Chicca Junior \\ Universidade Federal de Pernambuco \\ natal@virtual.ufc.br \\ Maria Eduarda Rabelo Duarte
Universidade Federal de Pernambuco
eduardarabelo@gmail.com
}

\begin{abstract}
We present a teaching experiment involving the use of digital prototyping technologies in a pedagogical method inspired on the challenge based learning method. This method is a problem-based-learning improvement relying on the autonomy of the student to identify subjects and problems of their interest instead of solving ready ones presented by teachers. Our study evaluates the use of the method for teaching design and project support tools. The classes took place in the Federal University of Pernambuco with students from different areas as architecture, mechanical engineering and design. The usage of this method leads to rich and creative solutions that could be concretized in the form of prototypes created with rapid prototyping and digital fabrication technologies.
\end{abstract}

Keywords: Problem-Based-Learning; Digital prototyping; teaching methods.

\section{Introdução}

Este artigo tem como objetivo apresentar um experimento realizado em práticas pedagógicas através do uso do método de Aprendizagem Baseada em Desafios (Challenge Based Learning, CBL) em conjunto com o ensino e aplicação de ferramentas de prototipagem digitais no desenvolvimento de projetos. A disciplina foi oferecida pelo curso de Licenciatura em Expressão Gráfica da Universidade Federal de Pernambuco (UFPE), no primeiro semestre de 2016, integrando diversas áreas de conhecimento e departamentos. Conforme apontado por Braida (2014), a interdisciplinaridade não está apenas no ato de integrar e confrontar diferentes disciplinas já existentes, mas sim construir um projeto comum e novo que estimule os alunos a construir o conhecimento de conceitos comuns e plurais. Apesar da falta de estímulo e das restrições burocráticas professores buscam a interação com outros docentes ou mesmo com a participação de diversos professores e este tipo de experiência enriquece os resultados de projetos e do ensino-aprendizado em geral. Da mesma forma, nossa proposta de experimento do uso da prototipagem digital dentro de uma disciplina de projeto surgiu através da parceria entre os cursos de Design e Expressão Gráfica, ambos do Centro de Artes e Comunicação (CAC) da UFPE. Apesar de estar inserida dentro do curso de Licenciatura em Expressão Gráfica, a disciplina foi aberta também aos cursos de Bacharelado em Arquitetura e Urbanismo, Design e Engenharias. Ela buscou integrar alunos de diferentes cursos dentro de um mesmo ambiente, e com objetivo de estimular a colaboração interdisciplinar e autonomia dos estudantes na criação e produção de artefatos auxiliados pela tecnologia de prototipagem digital. $O$ curso teve a duração de 90 horas e propôs uma introdução aos métodos, técnicas e ferramentas de prototipagem digital utilizando uma cortadora a laser e impressoras 3D recém adquiridas para o laboratório de prototipagem digital do departamento de expressão gráfica. Esta disciplina resultou na estruturação e surgimento do Grupo de Experimentos em Artefatos 3D (Gr3D), laboratório responsável por introduzir, ensinar e difundir as ferramentas de prototipagem digital aplicadas ao processo projetual através de oficinas, disciplinas, projetos de pesquisa e extensão. $\mathrm{O}$ método $\mathrm{CBL}$ foi utilizado para a resolução dos projetos, baseado no paradigma do ensino baseado em problemas que, além de guiar o semestre, ainda coordenaria a complementaridade dos alunos de 4 áreas diferentes. A disciplina foi estruturada de modo a promover a experimentação e completa compreensão dos alunos quanto às diferentes etapas de um projeto de produto além do aprendizado prático das ferramentas de prototipagem digital como parte integrada ao processo e não apenas como ferramenta de produção do produto final. Buscamos também validar o método como instrumento motivador e indutor de propostas inovadoras buscando resolver problemas reais e de interesse dos alunos. O uso deste método levou a soluções ricas e criativas concretizadas sob a forma de protótipos. As respostas dos questionários aplicados e os resultados alcançados na disciplina nos levam a concluir que houve grande entusiasmo e satisfação por parte dos alunos que, exercitaram o trabalho em grupo hoje, são capazes de circular entre as diferentes iniciativas locais do tipo FabLabs entre outros laboratórios de prototipagem e grupos 
de trabalho interdisciplinares e plurais para concretizar futuros projetos acadêmicos e profissionais. Esta é uma das visões da resiliência que nós apontamos com este artigo que é o de promover o aprendizado baseado na cooperação e na construção de comunidades acadêmicas realmente transdisciplinares e capazes de soluções inovadoras pois diversificadas em seus espectros de ações.

\section{Contexto}

O departamento de expressão gráfica da Universidade Federal de Pernambuco tem como missão o ensino de desenho técnico e geometria gráfica em diversos cursos da instituição. Em Arquitetura, Design e nas Engenharias, o Departamento de Expressão Gráfica é responsável pela formação básica em técnicas de desenho manual de representações tridimensionais (axonometria cônica, axonometria ortogonal, e sistema mongeano), mas também planificações e construções com instrumentos. Além das disciplinas interdepartamentais, o departamento ainda abriga uma licenciatura que forma alunos para atuar no campo da Educação Básica, mais especificamente no ensino de nível Médio e Médio Integrado na área de Geometria Gráfica e suas aplicações. No começo dos anos 90, o curso passou por uma mudança no seu perfil, com o objetivo de buscar adequar-se às necessidades do mercado, aproximando o seu egresso das denominadas "novas tecnologias", vinculadas aos instrumentos computacionais (Bellemain \& Galvão, 2013). O curso se equipou de laboratórios de informática e implementou uma grade de disciplinas eletivas que, segundo Bellemain \& Galvão (2013), permitiram a flexibilização do currículo, além de possibilitar a interação dos estudantes com outras áreas do conhecimento que faziam interface com o curso. Entre as disciplinas propostas se destacam: desenho de robótica, desenho em mecânica, modelagem digital entre outras tendências atuais em ensino e pesquisa de tecnologias de desenho e representação que enriqueceu o perfil dos alunos egressos. Por outro lado, os cursos de Arquitetura e Urbanismo e Design da UFPE se voltaram tradicionalmente para estratégias de ensino de projeto e concepção, delegando as técnicas de representação ao Departamento de Expressão Gráfica. O departamento passou a ser solicitado por estudantes e professores de Arquitetura e Design para formações na área de tecnologia e ferramentas de prototipagem e representação. Foi neste contexto que professores recém contratados experimentaram reagrupar duas disciplinas eletivas em tecnologia (90 horas no total) e abrir as matrículas para alunos externos ao departamento. Assim foi formada a disciplina integrada com alunos de Expressão Gráfica, Arquitetura, Design, Engenharia Civil e Engenharia Mecânica com um total de 32 alunos inscritos. Para orquestrar os diferentes níveis de conhecimento em tecnologia e projeto dos alunos de cursos e períodos diferentes optamos por experimentar um método de ensino baseado em projetos chamado CBL, Aprendizagem Baseada em Desafios (Challenge Based Learning) pela sua estrutura que promove e estimula a transdisciplinaridade e estimula a autonomia dos alunos em definir e gerenciar ideias e ações dentro de um grupo de projeto.

\section{Aprendizagem Baseada em Desafios}

A Aprendizagem Baseada em Desafios (Challenge Based Learning) é um método de ensino dentro do universo dos métodos denominados 'baseados em projetos'. Segundo Braida (2014), a Aprendizagem Baseada em Projetos (ABP) consiste em uma modalidade de aprendizagem de caráter ativo e colaborativo, que enfatiza as atividades de projeto, cuja principal característica é a construção coletiva do conhecimento interdisciplinar e centrada no aluno. "Aprendizagem Baseada em Projetos (...) busca capacitar os alunos para os desafios da contemporaneidade, integrando, de forma cooperativa, disciplinas, áreas e campos do saber. Com esse método, os trabalhos (inter, multi e trans) disciplinares ganham relevância, bem como aqueles que abordam temas transversais" (BRAIDA, 2014, p.143). Este método de aprendizagem promove a integração direta entre a teoria e a prática, resultando na apresentação de uma solução para um problema relacionado com uma situação, sempre que possível, mais próxima da realidade. Devido a suas características, Braida (2014) afirma que os métodos baseados em projetos estimulam a consciência do aluno para sua participação ativa no processo de aprendizagem, cuja forma de ação se dá por meio da construção de novos conhecimentos, sobretudo fundamentada em experiências cotidianas. Este paradigma enaltece a ideia do aprender fazendo e de que o conhecimento de longa duração é melhor construído com a vivência e concretização de ideias.

O Método CBL (retoma a ideia de que alunos se engajam e aprendem se envolvidos em atividades práticas e livres ao invés de participarem apenas como observadores ou plateia de uma aula. Ela também traz a ideia do desafio, ao invés de problemas, como base para buscar e solucionar problemas cotidianos delegando a busca pelos problemas aos estudantes.

O Challenge Based Learning (Apple Inc., 2011) se apresenta como uma estrutura em etapas e centrada nos problemas contemporâneos levantadas pelos estudantes. Em outros métodos de ensino, os problemas ou projetos propostos pelos professores podem não fazer parte dos interesses dos alunos. O método estimula o estudante a buscar um tema e um desafio e que esteja no escopo e contexto que seu interesse e contexto. $\mathrm{O}$ framework $\mathrm{CBL}$ acontece em 5 fases intituladas: Big Idea, Essential Question, Challenge, Solution e Guiding Questions.

\section{Big Idea}

A metodologia CBL começa com a definição de uma grande ideia (big idea), um conceito amplo que pode ser explorado de várias maneiras, tem como objetivo ser envolvente e ter grande importância para os alunos. Segundo o documento principal do método (CHALLENGE..., 2016), uma grande ideia é importante em uma escala global e que os alunos podem trabalhar para adquirir profundidade em conhecimentos de conteúdo multidisciplinar e compreensão que é exigido pelo nível do curso. Uma big idea é um tema geral como temas da atualidade no jornal do dia, por exemplo. Outros exemplos de 
big idea podem ser saúde, acessibilidade ou ainda, refugiados. Para esta disciplina, evitando uma dispersão de temas, parte da big idea foi estabelecida pelos professores e se resumia a palavra 'brincar'.

\section{Essential Question}

A essential question é uma pergunta que liga a big idea ao cotidiano. É um questionamento orientador que leva os alunos à pesquisa e foca em uma ação concreta.

\section{Challenge}

O challenge transforma a essential question em uma "chamada para a ação", levando os alunos para focar seus esforços e interesses. O challenge se apresenta como uma frase diretiva e que costuma começar com um verbo.

\section{Solution}

Finalmente o aluno precisa transformar o desafio proposto em algo utilizável e real juntado todas as ideias em algo com um propósito para sua sociedade. A solução é a descrição do produto em detalhes que será refinada até a conclusão do projeto.

\section{Guiding Questions}

Ao longo do processo, os estudantes criam perguntas que guiam e afunilam suas pesquisas. As guiding questions são perguntas que levam a pesquisa de questões teóricas e práticas como o uso de ferramentas ou materiais.

\section{Organização e estrutura do curso}

O curso aconteceu em encontros de 6 horas, nas terças a tarde, no primeiro semestre de 2016. Os alunos se encontravam em uma sala ao lado do laboratório GREA3D. As aulas foram separadas segundo as etapas do método (Big Idea, Essential Question, Challenge, Solution e Guiding Questions). No primeiro encontro, foi apresentado o curso e formados os grupos que deveriam garantir uma mistura de áreas de conhecimento. Para a formação de grupos foi feito um brainstorm onde surgiram dezenas de temas apresentadas individualmente e dispostos em uma parede. Foi então pedido que os grupos fossem formados em torno de 6 destas idéias apresentadas, o que aconteceu sem problemas. As palavras selecionadas foram: animais, carnaval, gastronomia, inclusão, música e saúde.

Para preparar o segundo encontro, pedimos aos estudantes que escolhessem e visitassem um local específico da cidade e desenvolvessem antes de aula uma apresentação com a descrição de uma pessoa representativa deste local e com um cenário em uma versão simplificada do método de criação de personas em design (Pruitt \& Adlin, 2010). A partir da criação dessas personas, debatemos em sala e chegamos a uma essential question final - a linha de guia para o produto que planejaríamos em seguida, por exemplo, "como levar/estabelecer cuidados necessários aos animais abandonados? Durante a aula, os alunos apresentaram os slides e no fim revelaram suas perguntas do tipo essential question. "Como tornar a espera na fila do R.U. mais agradável? Como tornar o aprendizado dos elementos da música mais intuitivo para todos os tipos de alunos?" foram algumas delas. A essential question deveria gerar mais uma série de questionamentos para ajudar a responder à pergunta principal e como nova tarefa de casa eles deveriam procurar responder essas guiding questions.

No terceiro encontro eles deveriam nos mostrar informalmente as questões e buscas realizadas e construir junto com os professores o desafio (challenge) para novamente ser apresentado no final da aula. Estes desafios delinearam o escopo do projeto com exemplos como: "aliviar o calor durante o carnaval da cidade de Olinda" ou "auxiliar pessoas com deficiências motoras a desenhar" ou como "guiar calouros no prédio do centro de artes". Esta etapa deveria lançar um olhar sobre o problema principal, mas não propor ainda solução concreta.

Para a aula seguinte, os alunos deveriam finalmente chegar a uma solução e por meio de esboços e sketches simples e rápidos idealizar alguma solução. Para esta etapa, pedimos aos alunos que pesquisassem técnicas de ideação e usassem a que lhes parecesse mais adequada.

Com as fase CBL iniciadas, aulas seguintes foram dedicadas ao projeto e a participação dos professores foi de tutoria e guia de recursos para a pesquisa. Os alunos, a partir deste momento, estavam livres de usar as técnicas que lhes fosse mais adequada. Eles certamente estavam ávidos por usar as novas tecnologias, mas, naturalmente, viram a dificuldade de pular as etapas de prototipagem manual e o uso de esboços. Assim, a maioria dos grupos se lançou na concretização de ideias por meio de desenhos e modelos em massa de modelar e papelão.

O caráter mais prático da disciplina foi devido a adoção do método em que os alunos aprendem a projetar através da própria execução de projetos. Este método é baseado em Bonsiepe et al. (1984) que afirmam que entre as diversas formas de ensinar projeto, destacam-se três:

- O método de abandono à própria sorte: o aluno recebe todas as informações técnicas, econômicas, culturais, etc., ficando com a tarefa de assimilá-las e transformá-las num projeto. O docente limita a sua participação a uma ocasional visita na sala de projeto;

- O método de osmose: esse funciona na presença de um grã-mestre, ao qual o aluno trata de copiar. Neste caso, os autores afirmam que tanto a crítica quanto a autonomia dificilmente podem se desenvolver num ambiente desse tipo;

- O método baseado na hipótese de que a melhor forma de aprender a projetar é projetar mesmo: utiliza-se, nesse caso, um método de diálogo. Para os autores, o docente perde a responsabilidade de saber tudo. Ele expõe a sua situação de não saber a solução previamente, colocando-se ao mesmo nível do aluno, participando diretamente nas tentativas de resolver um problema.

Em relação ao ensino do projeto de produto, Bonsiepe et al. (1984), classificam de acordo com três enfoques diferentes:

- O modelo bengala: o docente ajuda o aluno a ir em frente. Proporciona a maior parte das informações técnicas, préestruturando o campo no qual deve buscar uma solução; 
O modelo guia: o docente orienta o aluno que já se move com uma maior autonomia, interferindo só ocasionalmente no processo;

- O modelo consultor: o docente acompanha a marcha livre do aluno, limitando sua função a uma intervenção crítica ocasional;

- O modelo guia: o modelo adotado pela disciplina, o qual acompanha o desenvolvimento dos trabalhos dos alunos, ajudando a solucionar eventuais dúvidas e intervindo pontualmente através da divisão em tarefas semanais com apresentações e discussões das etapas do projeto. Associado à metodologia $\mathrm{CBL}$, tanto os professores como os alunos tinham voz ativa nos comentários, sugestões e decisões, reforçando o caráter de tutores e aprendizes a todos os participantes da disciplina. As discussões ao final de cada apresentação semanal contribuíram para os grupos refinarem cada vez mais as ideias de seus projetos em conjunto com estudos e resultados obtidos através do desenvolvimento de protótipos.

\section{Prototipagem digital aplicada à disciplina de projeto}

As ferramentas tradicionais como o lápis e o papel ganharam no computador um aliado capaz de produzir representações finais de projeto, mas também novas formas de esboços em fases de geração de ideias. Ferramentas tradicionais e digitais auxiliam na construção de formas simples mas permitem agora explorar modelos tridimensionais complexos com exatidão geométrica e matemática, a partir de programas gráficos e ferramentas de simulação, voltados ao desenvolvimento de projetos.

De acordo com Fontoura (2009), no campo de desenho técnico, as pranchetas, a régua de cálculo e as antigas canetas nanquim tornam-se obsoletas. O uso dos meios digitais e sistemas CAD, CAE, CAM e/ou programas de animação, modelagem tridimensional, realidade virtual aplicados a prototipagem/ prototipação virtual (virtual prototyping) e prototipagem digital (digital prototyping) proporcionam mudanças na maneira de se pensar o objeto. Eles permitem representar com precisão e, desenvolver análises e estudos de viabilidade técnica além de realizar rapidamente correções e alterações nos projetos e interagir com os processos de fabricação. Segundo Rufca (2012), estas ferramentas foram desenvolvidas para atender as necessidades de melhoria nos processos de análise das soluções propostas e tomadas de decisão, assim como viabilizar o processo de fabricação, possibilitando soluções mais ousadas.

Ao longo de toda a disciplina, os alunos foram estimulados a utilizar variadas ferramentas de representação para o desenvolvimento de protótipos utilizados como suporte à geração de ideias, refinamento formal, soluções projetuais e validação do projeto. No primeiro momento do curso, logo após definirem a solução, grande parte dos alunos utilizaram esboços e modelos físicos feitos de forma manual, modelos digitais em CAD, modelos físicos materializados através do corte à laser e também de impressão 3D, que podem ser vistos através de alguns exemplos mostrados na figura 1. Os professores incentivaram a utilizar qualquer material, técnica ou ferramenta que pudesse auxiliar os alunos a compreender melhor as etapas do processo projetual em busca da solução para o problema proposto.

Em relação ao ensino do uso de softwares, para auxiliar na criação dos modelos digitais, foram realizadas aulas técnicas com oficinas de 123D Make, da Autodesk voltada à criação de arquivos para a ferramenta de corte à laser, e Rhinoceros, da Robert McNeel \& Associates para criar os modelos digitais tridimensionais. Apesar das oficinas terem trabalhado apenas com estes softwares, não foi cobrado dos alunos a obrigatoriedade em utilizar nenhum desses dois ao longo da disciplina. Eles foram apenas sugeridos e cabia ao aluno escolher quais os softwares mais adequados às suas necessidades e desenvolvimento dos projetos. Da mesma forma, os alunos também seriam responsáveis pelo aprendizado e eventual aprofundamento na utilização dos softwares escolhidos.

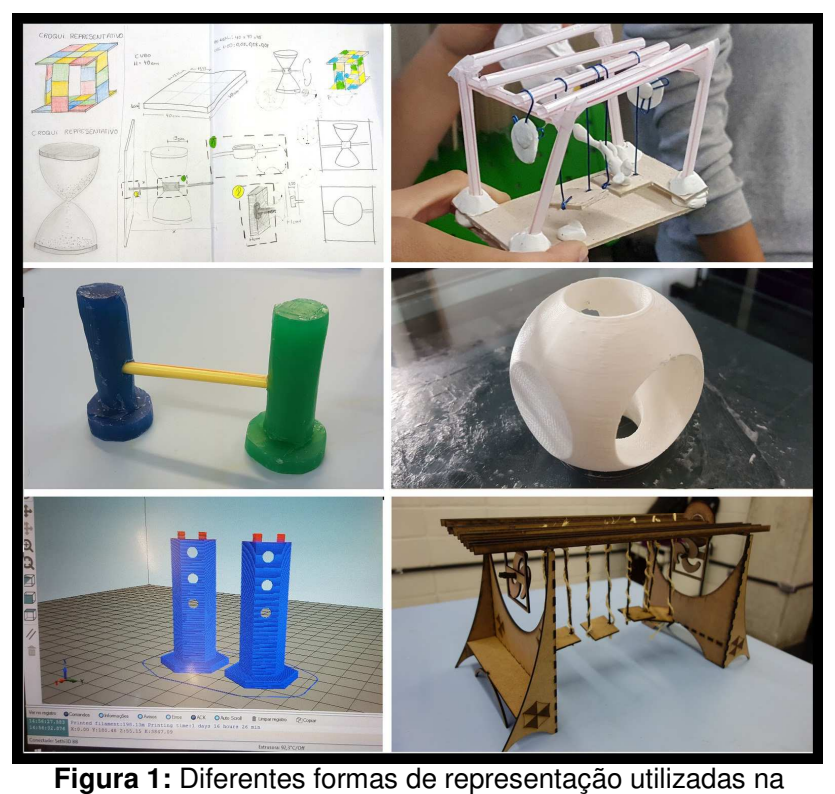
disciplina. (Imagens produzida pelos autores).

\section{Dificuldades verificadas no uso das ferramentas}

A impressão 3D de modelos físicos, durante as aulas, foi bastante conturbada pela inexperiência dos professores em relação a seus ajustes e, consequentemente, dificuldade em não saber reduzir o tempo de materialização de cada arquivo, levando muito tempo para concluir cada peça. A previsão do tempo estimado de impressão também apresentava bastante diferença entre o indicado pelo software e o tempo real, sempre levando muito mais tempo para o término. Com isso, a solução encontrada foi atender os alunos, durante as aulas, em uma espécie de birô de serviços onde traziam os seus arquivos digitais que posteriormente eram entregues já impressos a eles. Como resultado, os alunos, apesar de acompanharem as impressões de seus trabalhos, acabaram não passando pelo aprendizado pretendido em relação a configuração e ao uso da impressora 3D durante a disciplina. 
Ainda a respeito da impressão 3D, ao ganhar mais experiência no uso do software e do equipamento, a dificuldade em conseguir imprimir os modelos foi diminuindo com o passar do tempo. No entanto, ainda existe uma diferença e dificuldade muito grande em simplesmente materializar um arquivo digital e obter exatamente o resultado desejado. Mais uma vez, vale reforçar que a ampla gama de opções no gerenciamento de impressão em equipamentos open source acaba resultando em uma liberdade maior nas configurações, em contrapartida, acarreta em um nível de dificuldade muito alto em saber identificar qual parâmetro deve ser ajustado para conseguir o resultado inicialmente pretendido.

Em relação ao corte a laser, apesar de terem sido oferecidas oficinas dedicadas ao ensino do uso do software, assim como aulas específicas para a preparação dos arquivos e para tirar dúvidas, muitos alunos tiveram dificuldades ou problemas de compatibilidade de seus modelos digitais no envio para a máquina de corte à laser. Com isso, muitos tiveram atrasos no desenvolvimento de seus projetos até conseguirem corrigir os arquivos e finalmente poder cortar os seus modelos.

\section{Questionários aplicados}

A disciplina contou com um questionário de avaliação aplicado ao final da disciplina. O questionário foi elaborado utilizando questões mistas, alternando entre a seleção de alternativas e outras dissertativas com campos para preenchimento das respostas. Foi aplicado apenas um modelo de questionário sendo o conteúdo e a ordem das perguntas as mesmas para todos os alunos. Deste modo, fica mais fácil coletar e cruzar as informações obtidas. A análise dos dados coletados se baseia na pesquisa qualitativa, ou seja, não se preocupa com representatividade numérica, mas, sim, com 0 aprofundamento da compreensão de informações. Após a coleta, os questionários passaram por uma etapa de préanálise e tratamento de seus resultados os quais serão apresentados a seguir.

\section{Avaliação dos resultados}

Ao todo, 23 alunos responderam o questionário, sendo 11 deles do curso de Licenciatura em Expressão Gráfica, 11 alunos do curso de Bacharelado em Arquitetura e Urbanismo e apenas 1 era aluno do curso de Bacharelado em Engenharia Civil. Dos questionários respondidos, não contou com nenhum aluno dos dois primeiros semestres, sendo que metade dos alunos da disciplina já cursavam os semestres intermediários e a outra metade já estava nos semestres finais de seus cursos.

Em relação às técnicas de prototipagem rápida, antes de cursar a disciplina, 2 alunos já conheciam apenas o corte à laser, 5 alunos conheciam apenas a impressão 3D, 13 alunos conheciam as duas e apenas 3 não conheciam nenhuma delas. Quanto aos softwares de modelagem 3D, 19 alunos já conheciam pelo menos um, enquanto 4 nunca haviam utilizado nenhum deles antes de cursar a disciplina. O mais utilizado foi o SketchUp (15 alunos), seguido do AutoCAD 3D (6 alunos), e empatados o Rhinoceros e o Revit com 2 alunos cada e o Artlantis e o ArchiCAD com 1 aluno cada.
Sobre o uso das técnicas de corte à laser e impressão 3D, 11 alunos responderam que elas ajudaram na etapa de geração de ideias. Entre eles, 7 afirmaram que as ferramentas auxiliaram nas soluções de possíveis problemas e melhorias para o projeto, 3 acreditam que ajudou nos estudos da construção do produto e 1 disse que auxiliou na definição da forma. Para os 12 alunos que responderam que elas não ajudaram, 8 deles preferiram utilizar outras formas de representação, 3 utilizaram apenas para a forma final do produto e 2 não responderam o motivo. Ainda em relação ao uso das técnicas de corte à laser e impressão 3D, 19 alunos responderam que as ferramentas ajudaram na etapa de criação do protótipo. 3 alunos responderam que não. Dos que responderam que elas ajudam, 12 alunos afirmam que elas contribuem com a etapa de testagem e verificação da funcionalidade do protótipo. Para 3 alunos, elas contribuem auxiliando na percepção formal do protótipo, em aspectos como escala, por exemplo. E para 2 alunos, as ferramentas contribuem no processo de acabamento por ter uma precisão maior do que os processos manuais de modelagem.

Os alunos também foram questionados em relação à dificuldade em modelar utilizando diversas técnicas e ferramentas. No processo manual de modelagem (tradicional), 4 alunos tiveram dificuldades em encontrar materiais adequados, 4 alunos criticaram a falta de habilidade no processo, 3 alunos não gostam da falta de precisão, seja no aspecto funcional ou estético, 3 alunos criticam a complexidade em ter que modelar algo em escala. Apenas 3 alunos disseram que não tiveram dificuldade nenhuma ao usar a técnica de modelagem manual.

Em relação aos softwares de modelagem digital, 14 alunos criticam a dificuldade em dominar as ferramentas, 4 alunos tiveram problemas de compatibilidade ao exportar os arquivos entre diferentes programas, apenas 1 aluno reclamou que 0 uso das ferramentas digitais restringe o processo criativo e 1 aluno teve dificuldades em relação ao ajuste de escala.

Entre as dificuldades em relação ao uso do corte à laser, o que mais se destaca são os problemas de compatibilidade dos arquivos gerados com o software da máquina (6 alunos citaram esse problema), seguido da dificuldade em gerar o arquivo de corte corretamente (5 alunos), e a dificuldade em operar o software na elaboração do arquivo (1 aluno). Apenas 1 aluno relatou que não teve problema algum.

No caso da impressão 3D, as dificuldades que mais se destacam são: os problemas com a escala dos modelos e dificuldade nos encaixes das montagens (6 alunos), demora na impressão dos arquivos (5 alunos), dominar o uso do software (3 alunos) e preparação dos arquivos (3 alunos). Assim como no corte à laser, apenas 1 aluno relatou que não teve problema algum.

Buscando verificar se a experiência dos alunos em relação ao uso da ferramenta foi positiva ou não, a próxima pergunta se refere ao uso da impressão 3D em seus futuros projetos. 14 alunos responderam que voltariam a utilizam a impressão 3D em seus projetos. 9 afirmaram que é uma ferramenta que auxilia a compreender melhor a forma, volumetria e encaixes do projeto que está sendo desenvolvido. 1 aluno disse que a impressão 3D auxilia em novas ideias e 1 aluno destacou a 
possibilidade que a ferramenta traz ao permitir realizar testes com protótipos físicos. 5 alunos disseram que não voltariam a utilizar impressão 3D, sendo 3 deles devido ao custo muito alto em se obter a ferramenta. 3 alunos disseram que ainda preferem a ferramenta de corte à laser devido a sua maior precisão na materialização.

Nos comentários finais do questionário a respeito da disciplina, os alunos elogiaram a iniciativa dos professores em apresentar as ferramentas de prototipagem rápida, e a oportunidade de ter mais contato com ferramentas tecnológicas aplicada a projetos. Entretanto, eles também reforçaram a dificuldade em ter que aprender a utilizar os softwares necessários para a execução de seus projetos. Alguns estranharam a estrutura dos acompanhamentos feitos pelos professores, que foi bem diferente do método tradicional de aula expositiva o qual muitos estão acostumados. Poucos alunos chegaram até a comentar que ficaram um pouco perdidos durante as aulas. Mas, no geral, grande parte da turma gostou de ter participado e aprovou a proposta da disciplina.

\section{Resultados}

O curso obteve sucesso e as vagas para o semestre seguinte esgotaram. A experiência de integração foi elogiada por toda a turma, assim como a complementaridade das competências individuais dos alunos. O perfil da turma foi bastante interessante ao integrar três cursos em uma mesma disciplina. A presença de diversos cursos em uma única disciplina permitiu dividir e mesclar os grupos, trazendo um caráter mais interdisciplinar aos projetos e, ao mesmo tempo, tirando os alunos de sua zona de conforto por não trabalhar junto de seus colegas de sala mais próximos. As soluções aos projetos propostos foram originais e sobretudo motivaram os alunos até o fim do semestre. No entanto, apesar da complementaridade, alguns grupos sofreram com a falta de capacitação anterior em softwares de modelagem e desenho. Mais da metade na turma já conhecia a ferramenta de corte à laser e impressão 3D. Mas conhecer não necessariamente representa saber utilizar. Tanto que, em relação ao uso de softwares, no geral, a turma não tinha muita experiência com modelagem 3D. O SketchUp foi apontado por um pouco mais da metade da turma como o software que eles já sabiam utilizar para modelagem 3D, possivelmente por ser gratuito e mais simples de mexer. Poucos já sabiam utilizar o Rhinoceros, que foi um dos softwares que contou com oficinas dentro da disciplina para aprender a operá-lo. Inclusive, um pouco mais da metade da turma apontou a falta de domínio em relação ao uso de softwares como um dos grandes impeditivos em utilizar as ferramentas digitais no desenvolvimento dos projetos. A falta de habilidade foi uma das grandes barreiras no processo tradicional de modelagem manual.

Os alunos apresentaram dificuldades e falta de experiência em relação ao uso de protótipos ao longo do processo projetual. Em relação aos meios de representação, muitos deles ficaram restritos apenas ao raciocínio projetual através das representações digitais por meio de softwares CAD e acabam não utilizando outros recursos para o estudo e elaboração do projeto. Apesar de ser pré-requisito da disciplina gerar modelos de estudos como ferramenta auxiliar no processo projetual, os alunos acabaram passando boa parte das aulas trabalhando em arquivos digitais, seja pela facilidade e praticidade no uso da ferramenta como também um pouco de resistência e bloqueio frente às novas ferramentas apresentadas. Possivelmente 0 bloqueio em relação à ferramenta de impressão 3D foi devido à dificuldade no seu manuseio e demora na materialização das peças e o corte à laser pela dificuldade do acesso do equipamento pois o laboratório de prototipagem digital ainda estava em fase de construção.

Outra percepção em relação ao aprendizado das ferramentas de prototipagem rápida é que grande parte dos grupos desenvolveram os seus modelos finais utilizando a ferramenta de corte à laser. Possivelmente devido à facilidade no aprendizado, familiaridade e até mesmo domínio maior na ferramenta. A impressão 3D foi utilizada apenas em poucos modelos que foram feitos mais pela obrigatoriedade da disciplina do que por serventia prática real nos processos projetuais.

Durante as aulas, os alunos também demonstraram falta de interesse em explorar melhor a etapa de geração de alternativas através de estudos variados, diferentes propostas, retroalimentação e reestudos em busca de soluções aos problemas projetuais. Além de se contentarem logo com as primeiras ideias que surgem, poucos promovem testes de validação do projeto como aspecto de solução de um determinado problema apenas para refinar aspectos estéticos da forma original. Com isso, todos os grupos acabaram apresentando um número muito reduzido de geração de alternativas (seja qual for o método de representação utilizado) e o resultado final pouco se difere dos estudos iniciais.

A falta de experiência dos professores com o equipamento recém-adquirido, aliado ao comportamento instável e as próprias limitações da impressora 3D acabaram gerando grandes esperas na materialização dos arquivos. Os constantes atrasos possivelmente resultaram na diminuição do interesse (por parte dos alunos) em utilizar a impressão 3D no processo cíclico de retroalimentação de protótipos conforme era esperado pela pesquisa. Contudo, ao final da disciplina, mais da metade dos alunos disseram ter interesse em voltar a utilizar impressão 3D em seus futuros projetos.

Ainda na parte prática, a turma se mostrou dividida em relação ao uso da prototipagem digital aplicada a etapa de geração de ideias no processo projetual. No entanto, boa parte da turma concorda que as ferramentas auxiliam na criação de protótipos. A testagem dos projetos, principalmente em relação à sua funcionalidade, através de protótipos foi um dos pontos mais destacados no uso das ferramentas de prototipagem digital.

Entretanto, apesar das dificuldades, a estrutura da disciplina demonstrou ser positiva em relação a estimular os alunos a trabalharem de forma colaborativa promovendo discussões, reflexões e também servir como incentivo a autonomia em avaliar soluções geradas por colegas. Nesta experiência já foi 
possível compreender algumas deficiências na estrutura do curso que já foram revistas e modificadas, o que resultou em novas propostas de disciplinas que, certamente, vão resultar em pesquisas e trabalhos futuros.

\section{Referencias}

Bellemain, F., \& Galvão, T. (2013). Nova licenciatura em expressão gráfica: parcerias para um futuro promissor. Presented at the graphica'2013 xxi simpósio nacional de geometria descritiva e desenho técnico e $x$ international conference on graphics engineering for arts and design, ufsc,florianópolis-sc.

Braida, F. (2014). Da Aprendizagem Baseada em Problemas à Aprendizagem Baseada em Projetos: estratégias metodológicas para o ensino de projeto nos cursos de Design à luz dos paradigmas contemporâneos. In Actas de Diseño n. 17, IX Encuentro Latinoamericano de Diseño 2014 - Diseño en Palermo. jul 2014, 142-146.
Bonsiepe, G., Kellner, P., \& Poessnecker, H. (1984). Metodologia Experimental: desenho industrial. Brasília: CNPq/ Coordenação editorial.

Apple Inc. (2011). Challenge based learning: A classroom guide. Technical report, Apple Inc., Cupertino, CA.

Fontoura, A. M. (2009, Apr 8). O desenho e o design. In abcDesign. Retrieved from http://www.abcdesign.com.br/porassunto/teoria/o-desenho-e-o-design/

Kokotsaki, D., Menzies, V. \& Wiggins, A. (2016). Project-based learning: a review of the literature. Improving schools, 19, 267277.

Rufca, S. (2012). Design de produto: técnicas e tecnologias de representação visual. Dissertação (Mestrado em Design) Universidade Anhebi Morumbi. São Paulo

Challenge Based Learning Guide. (2016, August 30). Retrieved from http://cbl.digitalpromise.org/2016/08/30/challenge-basedlearning-guide/

Pruitt, J., \& Adlin, T. (2010). The Persona Lifecycle: Keeping People in Mind Throughout Product Design. Morgan Kaufmann. 